Check for updates

Cite this: RSC Adv., 2017, 7, 37666

\title{
A highly-flexible cyclic-decavanadate ligand for interconversion of dinuclear- and trinuclear- cobalt(II) and manganese(II) cores $\dagger$
}

\author{
Tatsuya Maruyama, ' Yuji Kikukawa, (D) ab Hiroshi Sakiyama, (D) c Misaki Katayama, ${ }^{\text {d }}$ \\ Yasuhiro Inada ${ }^{d}$ and Yoshihito Hayashi (D) *a
}

\begin{abstract}
The structure transformation of multinuclear-metal-cores can change catalytic, optical, and magnetic properties. Cyclic decavanadate ligands exhibit versatility in the number and the direction of the coordination sites by changing the conformation to stabilize various multinuclear-metal-cores, while organic multinucleating ligands require specific design for each of the multimetal complexes due to their structure directing ability. The flexibility of cyclic decavanadate ligands is demonstrated here to achieve accommodation of dinuclear or trinuclear units by using the same ligand. The reaction of a dinuclearcobalt-core-containing decavanadate $\left[\mathrm{CO}_{2}\left(\mathrm{H}_{2} \mathrm{O}_{2} \mathrm{~V}_{10} \mathrm{O}_{30}\right]^{6-}(\mathrm{Co} 2)\right.$ with 1 equiv. of $\mathrm{Co}(\mathrm{OAc})_{2}$ $(\mathrm{OAc}=$ acetate $)$ gave a trinuclear-cobalt-core-containing decavanadate $\left[\mathrm{CO}_{3}\left(\mathrm{H}_{2} \mathrm{O}\right)(\mathrm{OAc}) \mathrm{V}_{10} \mathrm{O}_{30}\right]^{5-}(\mathrm{Co} 3)$ in high yield. The central cobalt core exhibited an incomplete-cubane-type structure. The decavanadate ring contracts to accommodate a smaller dinuclear unit by taking a wavy conformation and expands to accommodate the larger trinuclear unit. The reverse reaction quantitatively proceeded by the addition of 5 equiv. of $\left[\mathrm{VO}_{3}\right]^{-}$with respect to $\mathrm{Co}$. Although a trinuclear-manganese-core-containing decavanadate $\left[\mathrm{Mn}_{3}\left(\mathrm{H}_{2} \mathrm{O}\right)(\mathrm{OAc}) \mathrm{V}_{10} \mathrm{O}_{30}\right]^{5-}(\mathrm{Mn} 3)$ possesses the same structure as that of $\mathrm{Co}$, the addition of 5 equiv. of $\left[\mathrm{VO}_{3}\right]^{-}$yielded a different structure of a dinuclear-manganese-core-containing decavanadate $\left[\mathrm{Mn}_{2} \mathrm{~V}_{10} \mathrm{O}_{30}\right]^{6-}(\mathrm{Mn2})$ with two cyclic pentavanadate ligands sandwiching the manganese core. Thus, the conformations of the cyclic decavanadates are rearranged to respond to the central metal core structures. EXAFS study suggests both manganese complexes maintain the molecular structure in solution. The simultaneous analyses of the magnetic susceptibility data and the magnetization data revealed the switch of magnetic interaction modes from ferromagnetic in dinuclear complexes to mixed ferromagnetic and antiferromagnetic interactions in trinuclear complexes: the ferromagnetic interaction in dinuclear units of $\mathrm{Co} 2\left(\mathrm{~J}=8.05 \mathrm{~cm}^{-1}\right)$ and $\mathrm{Mn} 2\left(\mathrm{~J}=0.76 \mathrm{~cm}^{-1}\right)\left(H_{\text {ex }}=-J S_{1} S_{2}\right)$, and the ferromagnetic and antiferromagnetic interactions in $\operatorname{Co} 3\left(\mathrm{~J}=-1.59 \mathrm{~cm}^{-1}\right.$ and $\left.\mathrm{J}^{\prime}=13.6 \mathrm{~cm}^{-1}\right)$ and $\mathrm{Mn3}$ $\left(J=-2.20 \mathrm{~cm}^{-1}\right.$ and $\left.J^{\prime}=0.07 \mathrm{~cm}^{-1}\right)\left(H_{\mathrm{ex}}=-J S_{\mathrm{A} 1} S_{\mathrm{A} 2}-J^{\prime}\left[S_{\mathrm{A} 1} S_{\mathrm{B}}+S_{\mathrm{A} 2} S_{\mathrm{B}}\right]\right)$ were studied.
\end{abstract}

Accepted 24th July 2017

DOI: $10.1039 / \mathrm{c} 7 \mathrm{ra05941h}$

rsc.li/rsc-advances

\section{Introduction}

The design and functionalization of multinuclear-metal-cores have crucial importance in many fields such as catalysis, magnetism, electrochemistry, and photochemistry. ${ }^{\mathbf{1 , 2}}$ Multinuclear-metal-cores are also important in biological

${ }^{a}$ Department of Chemistry, Graduate School of Natural Science and Technology, Kanazawa University, Kakuma, Kanazawa 920-1192, Ishikawa, Japan. E-mail: hayashi@se.kanazawa-u.ac.jp

${ }^{b}$ JST, PRESTO, 4-1-8 Honcho, Kawaguchi 332-0012, Saitama, Japan

'Department of Science, Faculty of Science, Yamagata University, Kojirakawa, Yamagata 990-8560, Japan

${ }^{d}$ Department of Applied Chemistry, Graduate School of Life Sciences, Ritsumeikan University, 1-1-1 Noji-Higashi, Kusatsu 525-8577, Japan

$\dagger$ Electronic supplementary information (ESI) available. CCDC 1546869. For ESI and crystallographic data in CIF or other electronic format see DOI: $10.1039 / \mathrm{c} 7 \mathrm{ra} 05941 \mathrm{~h}$ systems such as in metalloenzymes and utilize the protein chains as a ligand to stabilize the metal core, and these systems also require a dynamic change in the number and direction of the coordination sites of the cores during the catalytic cycle. ${ }^{3,4}$

Multinuclear complexes are fine-tuned to achieve a specific property by using tailor made organic ligands in coordination chemistry. In the functional multimetal complexes, the specific ligand design is necessary to fit in metal coordination environments, for example, a dinucleating ligand for a dinuclear complex and a trinucleating ligand for a trinuclear complex..$^{5-17}$ The inorganic ligands, composed of metal-oxygen clusters, polyoxometalates, also stabilize multinuclear-metal-cores. ${ }^{18}$ The advantage in the inorganic ligands is its diverse properties in redox and electron-transfer properties, acidity, and solubility by optimizing constituent elements, structures, and counter cations. ${ }^{19}$ Although the typical Keggin- and Wells-Dawson type polyoxometalates have low coordination ability, the metastable 
lacunary polyoxometalates, ranging from mono- to hexalacunary ones, are utilized to accommodate metal cluster cores by offering more than four oxygen atoms as donor sites. The multinuclear-metal-core-containing polyoxometalates exhibit the greatest properties in a wide field of research. ${ }^{20-28}$ In addition, the reversible structure transformation of multinuclear metal cores with using $\left[\mathrm{SiW}_{10} \mathrm{O}_{36}\right]^{8-}$ ligands are reported. ${ }^{29,30}$ By addition of the required components, the reversible transformations between dinuclear- and tetranuclear-copper and cobalt cores are achieved. ${ }^{29,30}$ The water- and temperaturetriggered geometry control between cubane- and planer-type tetranuclear-cobalt-cores are demonstrated. ${ }^{31}$ These tailormade organic ligands or inorganic ligands have a rigid coordination configuration defined by the arrangement of oxygen and/ or nitrogen donor atoms. For the design of enzyme like flexible ligand system, the new ligand system that can meet variable coordination environments even for a different nuclearity of the metal cores has to be developed.

Vanadium-based polyoxometalates exhibit structural versatility based on three types of polyhedral units: tetrahedral $\mathrm{VO}_{4}$, square pyramidal $\mathrm{VO}_{5}$, and octahedral $\mathrm{VO}_{6} \cdot{ }^{32-34}$ Among these structural units, $\mathrm{VO}_{4}$-based polyoxovanadates construct a ring structure by corner-sharings of $\mathrm{VO}_{4}$ units. The cyclic polyoxovanadates act as ligands for various metal cores to form inorganic complexes, such as $\left[\operatorname{Ln}\left(\mathrm{VO}_{3}\right)_{n}\right]^{-n+3}(n=8,9,10$ : $\mathrm{Ln}=$ lanthanides(III)), $\left[\mathrm{Mn}_{2}\left(\mathrm{~V}_{5} \mathrm{O}_{15}\right)_{2}\right]^{6-},\left[\mathrm{Co}_{2}\left(\mathrm{OH}_{2}\right)_{2} \mathrm{~V}_{10} \mathrm{O}_{30}\right]^{6-}$, $\left[\mathrm{Ni}_{4}(\mathrm{OH})_{2}\left(\mathrm{OH}_{2}\right)_{6} \mathrm{~V}_{10} \mathrm{O}_{30}\right]^{4-}$, and $\left[\mathrm{Cu}_{2} \mathrm{~V}_{8} \mathrm{O}_{24}\right]^{4-} \cdot{ }^{35-39}$ The macrocyclic $\left[\mathrm{VO}_{3}\right]_{n}{ }^{n-}$ has a freedom of $\mathrm{V}-\mathrm{O}-\mathrm{V}$ bridge angles and one of two oxo-groups on each vanadium atom has coordination ability to the metal center. The number of coordination donor-atoms from $\left[\mathrm{VO}_{3}\right]_{n}{ }^{n-}$ can be varied by either one oxo-group join to the coordination to the metal center or two oxo-groups are remain free from coordination. The maximum coordination donor atoms from $\left[\mathrm{VO}_{3}\right]_{n}{ }^{n-}$ ligand is $n$. This flexible change of the number of donor-atoms and the spatial flexibility due to its conformational change allows the ligands to form versatile inorganic complexes with a different number of central metal nuclearity. The coordination sites on the metal core which is not occupied from the cyclic ligands is available to other ancillary ligands such as water ligands, and it provide the active site for exchange reaction to the other types of ligands. ${ }^{39-41}$ The inorganic complex may be a scaffold to construct a unique polyoxovanadate in a bowl-shape by removing the metal cores from $\left[\mathrm{Cu}_{2} \mathrm{~V}_{8} \mathrm{O}_{24}\right]^{4-}$ to give dodecavanadate $\left[\mathrm{V}_{12} \mathrm{O}_{32}(\mathrm{Cl})\right]^{5-} .^{42}$ The inorganic complexes by $\left[\mathrm{VO}_{3}\right]_{n}{ }^{n-}$ ligand have been investigated in a solid state with crystal structures, but this excellent flexibility may allow a dynamic transformation of the nuclearity of the metal cores even in solution state within the same ligand system. Here, we demonstrate the $\left[\mathrm{VO}_{3}\right]_{n}{ }^{n-}(n=5$ or 10) ligands respond to the change of central metal cores between dinuclear- and trinuclear-metal-cores and it adopts two types of completely different coordination sites that are different in coordination site number and the arrangements through the variable coordination modes of the same ligands (Fig. 1). We focused on the cobalt-core-containing polyoxovanadates because of the structural variety and their unique properties, such as magnetism, photochemistry, electrochemistry, and catalysis. ${ }^{43-49}$ We choose dinuclear-cobalt-core-containing polyoxometalate (Co2) for the first precursor, because Co2 possess the disk-type structure to which an additional cobalt cation can access to form a trinuclear-core, and two non-coordinating $\mathrm{VO}_{4}$ units which can work as the additional coordination donor groups. ${ }^{36}$ We successfully synthesize a novel trinuclear-cobalt-core-containing polyoxovanadate, $\left[\mathrm{Co}_{3}\left(\mathrm{H}_{2} \mathrm{O}\right)(\mathrm{OAc}) \mathrm{V}_{10} \mathrm{O}_{30}\right]^{5-}$ (Co3). Their reversibility and magnetic properties are also investigated.

\section{Experimental section}

\section{Instruments}

IR spectra were measured on a JASCO FT/IR-4100 using attenuated total reflection (ATR) method. Elemental analyses of C, H and $\mathrm{N}$ were performed by the Research Institute for Instrumental Analysis at Kanazawa University. The ICP-AES analyses were performed with iCAP 6300 instrument from Thermo Fisher Scientific. Magnetic susceptibilities of polycrystalline samples were measured on Quantum Design SQUID magnetometer operating between $2 \mathrm{~K}$ and $300 \mathrm{~K}$ under 1000 Oe magnetic field. The magnetic analyses, including susceptibility and magnetization simulation, and simultaneous fitting, were conducted by MagSaki(A), Magsaki(Tri), and MagSaki(Basic) software of MagSaki series. ${ }^{\mathbf{5 0 - 5 2}}$

\section{Materials}

$\mathrm{Mn}(\mathrm{OAc})_{2}, \mathrm{Co}(\mathrm{OAc})_{2}$, acetonitrile, and diethyl ether were obtained from Wako Chemical and used as received. $\left\{\mathrm{Et}_{4} \mathrm{~N}\right\}\left[\mathrm{VO}_{3}\right]{ }^{53}$ $\left\{\mathrm{Et}_{4} \mathrm{~N}\right\}_{6}\left[\mathrm{Mn}_{2}\left(\mathrm{~V}_{5} \mathrm{O}_{15}\right)_{2}\right],{ }^{36} \quad\left\{\mathrm{Et}_{4} \mathrm{~N}\right\}_{6}\left[\mathrm{Co}_{2}\left(\mathrm{H}_{2} \mathrm{O}\right)_{2} \mathrm{~V}_{10} \mathrm{O}_{30}\right],{ }^{36} \quad$ and $\left\{\mathrm{Et}_{4} \mathrm{~N}\right\}_{5}\left[\mathrm{Mn}_{3}(\mathrm{OAc})\left(\mathrm{H}_{2} \mathrm{O}\right) \mathrm{V}_{10} \mathrm{O}_{30}\right]^{39}$ were synthesized according to the reported procedures.

\section{EXAFS studies}

The extended X-ray analysis fine structure (EXAFS) measurements for solid samples and propylene carbonate solution samples were performed at $295 \mathrm{~K}$ using the BL-3 at the SR

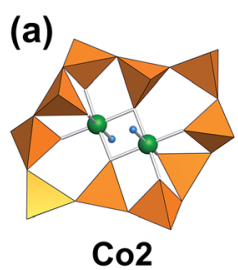

(b)

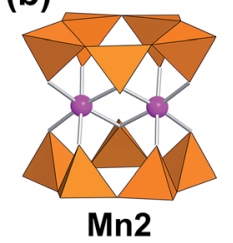

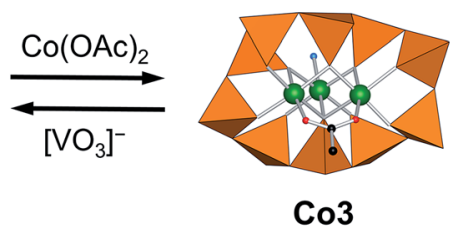

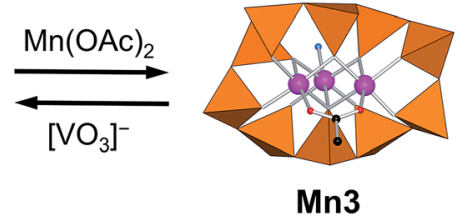

Fig. 1 Interconversion of decavanadates with dinuclear- and trinuclear- (a) cobalt and (b) manganese cores. Orange tetrahedra represent $\mathrm{VO}_{4}$ units. Green, pink, black, red and blue spheres represent cobalt atoms, manganese atoms, carbon atoms, oxygen atoms of acetate, and water oxygen atoms, respectively. 
Center of Ritsumeikan University (Kusatsu, Japan). All samples were prepared in an anaerobic environment using a polyethylene glove bag filled with dry nitrogen because of the hygroscopic nature of the samples. Solid samples were diluted with boron nitride and pressed into pellets of $20 \mathrm{~mm}$ diameter. The pellets were sealed in a polyethylene bag in order to avoid moisture. Sample solutions with manganese concentrations of $0.1 \mathrm{mM}$ were prepared by dissolving the powder of each complex in propylene carbonate at $353 \mathrm{~K}$. The solution samples were sealed in a transparent plastic bag with approximate thickness of $1.5 \mathrm{~mm}$ through a handmade cell. The white synchrotron radiations were monochromatized by a $\operatorname{Si}(220)$ double-crystal monochromator. Data collections of the Mn and Co K-edge absorption edges were performed in transmission mode. EXAFS data were analyzed with the ATHENA and ARTEMIS programs in the Demeter package. ${ }^{54}$

\section{X-ray crystallographic analysis}

Diffraction measurements of $\mathbf{C o 3}$ were made on a Rigaku/MSC Mercury diffractometer with graphite-monochromated Mo K $\alpha$ radiation $(\lambda=0.71069 \AA)$ at $83 \mathrm{~K}$. The data of $\mathbf{C o 3}$ were collected and processed using CrystalClear program. ${ }^{55}$ Numerical absorption corrections were applied by using Crystalclear and corrections for Lorenz and polarization effects were performed. The structural analysis was performed using CrystalStructure ${ }^{56}$ and ShelXle ${ }^{57}$ for Windows software. The structure was solved by SHELXS-2014 ${ }^{58}$ (direct methods) and refined by SHELXL-2014. ${ }^{58}$ Non-hydrogen atoms were refined anisotropically. Hydrogen atoms are positioned geometrically and refined using a riding model. CCDC 1546869 (for Co3) contain the supplementary crystallographic data. $\dagger$

\section{Synthesis of $\mathrm{Co3}$}

$\left\{\mathrm{Et}_{4} \mathrm{~N}\right\}\left[\mathrm{VO}_{3}\right](230 \mathrm{mg}, 1.0 \mathrm{mmol})$ was dissolved in acetonitrile $(3 \mathrm{~mL})$, and $\mathrm{Co}(\mathrm{OAc})_{2} \cdot 4 \mathrm{H}_{2} \mathrm{O}(125 \mathrm{mg}, 0.5 \mathrm{mmol})$ was added. The resulting solution was stirred for $3 \mathrm{~h}$ at room temperature. The precipitates formed were collected, washed with acetonitrile, and dried to afford $85 \mathrm{mg}$ of $\mathbf{C o 3}$ (45\% yield based on V). Recrystallization of $\mathbf{C o 3}$ from an acetonitrile gave rod shaped crystals suitable for X-ray crystallographic structure analysis. Anal. Calcd (\%) for $\left\{\mathrm{Et}_{4} \mathrm{~N}\right\}_{5}\left[\mathrm{Co}_{3}(\mathrm{OAc})\left(\mathrm{H}_{2} \mathrm{O}\right) \mathrm{V}_{10} \mathrm{O}_{30}\right]$ : C, 26.63; $\mathrm{H}$, 5.59; N, 3.70. Found: C, 26.51; H, 5.67; N, 3.95. IR (ATR, $\mathrm{cm}^{-1}$ ): 3465, 3297, 2988, 2950, 1650, 1573, 1484, 1462, 1440, 1418, 1395, 1307, 1174, 1003, 979, 959, 944, 903, 849, 826, 784, 765, 710, 693, 668, 612, 552 .

\section{Transformation of $\mathrm{Co} 2$ into $\mathrm{Co} 3$}

Compound Co2 (190 mg, $100 \mu \mathrm{mol})$ was immersed in acetonitrile $(5 \mathrm{~mL})$, followed by the addition of $\mathrm{Co}(\mathrm{OAc})_{2} \cdot 4 \mathrm{H}_{2} \mathrm{O}(25 \mathrm{mg}$, $100 \mu \mathrm{mol}$ ), giving a green suspension solution. The solution was stirred for $2 \mathrm{~h}$ at room temperature. Then, the yellow-green precipitates formed were collected, washed with acetonitrile, and dried to afford $166 \mathrm{mg}$ of $\mathbf{C o 3}$ (87\% yield based on Co2). The formation of Co3 was confirmed by comparing IR with authentic samples.

\section{Transformation of $\mathrm{Co3}$ into $\mathrm{Co} 2$}

Compound Co3 (38 mg, $20 \mu \mathrm{mol})$ was dissolved in acetonitrile $(10 \mathrm{~mL})$, followed by the addition of $\left\{\mathrm{Et}_{4} \mathrm{~N}\right\}\left[\mathrm{VO}_{3}\right](23 \mathrm{mg}, 100$ $\mu \mathrm{mol})$, giving a green solution. The solution was stirred for $2 \mathrm{~h}$ at room temperature. To the solution was added diethyl ether, and the resulting solution was stood for 1 day at room temperature. Then, the precipitates formed were collected, washed with acetonitrile, and dried to afford $51 \mathrm{mg}$ of $\mathbf{C o 2}(87 \%$ yield based on Co3). The formation of Co3 was confirmed by comparing IR with authentic samples.

\section{Transformation of Mn2 into Mn3}

Compound Mn2 (94 mg, $50 \mu \mathrm{mol}$ ) was immersed in acetonitrile $(10 \mathrm{~mL})$, followed by the addition of $\mathrm{Mn}(\mathrm{OAc})_{2} \cdot 4 \mathrm{H}_{2} \mathrm{O}(12 \mathrm{mg}, 50$ $\mu \mathrm{mol})$, giving an orange solution. The solution was stirred for $2 \mathrm{~h}$ at room temperature, and a red-orange suspension was obtained. The resulting solution was concentrated to ca. $1 \mathrm{~mL}$. Then, the orange precipitates formed were collected, washed with acetonitrile, and dried to afford $91 \mathrm{mg}$ of Mn3 (96\% yield based on Mn2). The formation of Mn3 was confirmed by comparing IR with authentic samples.

\section{Transformation of Mn3 into Mn2}

Compound Mn3 (94 mg, $50 \mu \mathrm{mol}$ ) was immersed in acetonitrile $(10 \mathrm{~mL})$, followed by the addition of $\left\{\mathrm{Et}_{4} \mathrm{~N}\right\}\left[\mathrm{VO}_{3}\right](57 \mathrm{mg}, 250$ $\mu \mathrm{mol})$, giving an orange solution. The solution was stirred for $2 \mathrm{~h}$ at room temperature, and a red-orange suspension was obtained. The resulting solution was concentrated to $c a .1 \mathrm{~mL}$. Then, the orange precipitates formed were collected, washed with acetonitrile, and dried to afford $125 \mathrm{mg}$ of $\mathbf{M n} 2$ (88\% yield based on Mn3). The formation of Mn2 was confirmed by comparing IR with authentic samples.

\section{Results and discussion}

\section{Synthesis of $\mathrm{Co3}$ and reversible transformation between $\mathrm{Co} 2$ and $\mathrm{Co3}$}

By the reaction of $\mathrm{Co} 2$ with 1 equiv. of $\mathrm{Co}(\mathrm{OAc})_{2}$ with respect to Co2 in acetonitrile, the precipitates of $\mathbf{C o 3}$ were obtained in $87 \%$ yield based on Co2 (Fig. 1a). The IR spectrum of $\mathbf{C o 3}$ showed the characteristic bands due to asymmetrical and symmetrical stretching vibration of acetate at $1573 \mathrm{~cm}^{-1}$ and $1418 \mathrm{~cm}^{-1}$ (Fig. 2A), respectively. The peak separation value of these two peaks $\left(\Delta=155 \mathrm{~cm}^{-1}\right)$ was in the range of those of bridging acetate. ${ }^{59,60}$ In the fingerprint region of the polyoxovanadate frameworks $\left(1100-500 \mathrm{~cm}^{-1}\right)$, the spectrum was different from that of Co2. The weak peak of terminal $\mathrm{V}-\mathrm{O}$ stretching vibration around $1000 \mathrm{~cm}^{-1}$ that was the characteristic feature of the $\mathrm{VO}_{4}$-based circular polyoxovanadates, was observed..$^{35-39}$ Single crystals suitable for X-ray crystallographic analysis were successfully obtained from the saturated acetonitrile solution. The bond valence sum values of cobalt (1.99-2.07) and vanadium (4.98-5.06) indicate that respective valences are +2 and +5 . The anion structure of $\mathbf{C o 3}$ was composed of a $\mathrm{VO}_{4}$-based cyclic decavanadate ligand and a trinuclear-cobalt-core. The coordination sites of trinuclear-cobalt 

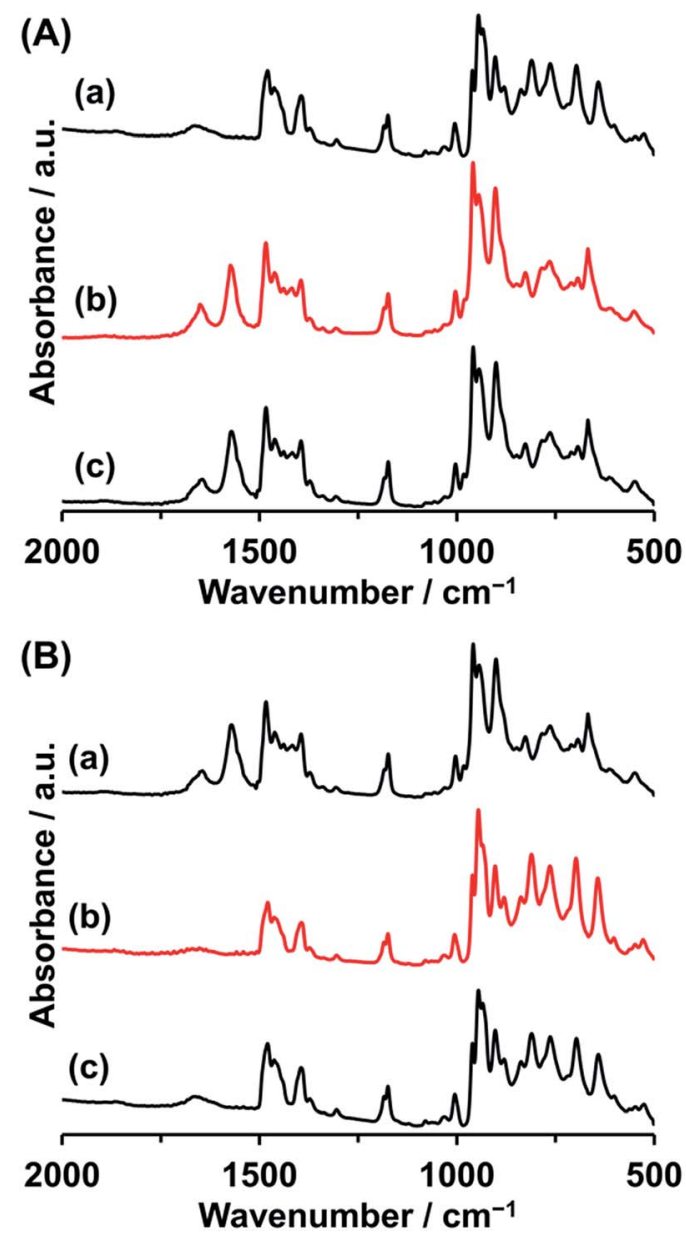

Fig. 2 (A) IR spectra of (a) Co2, (b) Co2 treated with 1.0 equiv. of $\mathrm{Co}(\mathrm{OAc})_{2}$, and (c) Co3. (B) IR spectra of (a) Co3, (b) Co3 treated with 5.0 equiv. of $\left\{\mathrm{Et}_{4} \mathrm{~N}\right\}\left[\mathrm{VO}_{3}\right]$, and (c) $\mathrm{Co} 2$.

units are occupied by thirteen oxygen atoms: one oxygen atom from aquo-ligand, two oxygen atoms from acetate group and ten oxygen atoms from $\mathrm{VO}_{4}$ units (Table $\mathrm{S} 1 \dagger$ ). The X-ray data and elemental analyses show that the formula of $\mathbf{C o 3}$ is $\left\{\mathrm{Et}_{4} \mathrm{~N}\right\}_{5}\left[\mathrm{Co}_{3}\left(\mathrm{H}_{2} \mathrm{O}\right)(\mathrm{OAc}) \mathrm{V}_{10} \mathrm{O}_{30}\right]$. The formation of $\mathrm{Co} 3$ from $\mathrm{Co} 2$ is expressed by eqn (1).

$$
\begin{aligned}
& \left\{\mathrm{Et}_{4} \mathrm{~N}\right\}_{6}\left[\mathrm{Co}_{2}\left(\mathrm{H}_{2} \mathrm{O}\right)_{2} \mathrm{~V}_{10} \mathrm{O}_{30}\right]+\mathrm{Co}(\mathrm{OAc})_{2} \rightarrow \\
& \quad\left\{\mathrm{Et}_{4} \mathrm{~N}\right\}_{5}\left[\mathrm{Co}_{3}\left(\mathrm{H}_{2} \mathrm{O}\right)(\mathrm{OAc}) \mathrm{V}_{10} \mathrm{O}_{30}\right]+\left\{\mathrm{Et}_{4} \mathrm{~N}\right\} \mathrm{OAc}+\mathrm{H}_{2} \mathrm{O}
\end{aligned}
$$

The trinuclear cobalt core was the incomplete-cubane type structure with $\mathrm{Co}_{3} \mathrm{O}_{4}$ fragment. The value of the bond lengths and bond angles are similar to those of the previously reported compounds with the incomplete-cubane-type $\mathrm{Co}_{3} \mathrm{O}_{4}$ cores. ${ }^{61-63}$ The distribution of the Co-O bond lengths in $\mathbf{C o 3}$ was small in the range. Such an uniform incomplete-cubane framework was only observed in the compound with each of metal coordinated by the same small ligands without the structural bulkiness, ${ }^{61-63}$ indicating that the cyclic decavanadate ligand comfortably offers an ideal donor-sites arrangement by adjusting their conformation to the central $\mathrm{Co}_{3} \mathrm{O}_{4}$ core. The bridging acetate ligand restricts the Co $\cdots$ Co distance in a shorter length of $3.00 \AA$ leaving other inter-metallic distances at 3.30 Å. Even Co2 and Co3 are accommodated by the same decavanadate ligands, their conformations were different each other. The decavanadate ligand in Co2 provides eight coordination donors to the central cobalt core. The $\mathrm{V}_{10} \mathrm{O}_{10}$ ring in $\mathrm{Co} 2$ contracts by taking the wavy conformation composed from the five zig-zag chain-blocks (V1-V2-V3, $\mathrm{V} 3-\mathrm{V} 4-\mathrm{V} 5, \mathrm{~V} 5-\mathrm{V} 1 *-\mathrm{V} 2 *, \mathrm{~V} 2 *-\mathrm{V} 3 *-\mathrm{V} 4 *$, and $\left.\mathrm{V} 4{ }^{*}-\mathrm{V} 5 *-\mathrm{V} 1\right)$ and two of the $\mathrm{VO}_{4}$ units are not involved in the coordination (Fig. 3a). On the other hand, decavanadate ligand in $\mathbf{C o 3}$, expands that all $\mathrm{VO}_{4}$ units were coordinated to the central cobalt core. The $\mathrm{V}_{10} \mathrm{O}_{10}$ ring structure in $\mathrm{Co3}$ is considered to be constructing from two kinds of zig-zag chain-blocks: (V3-V4-V5 and V5-V6-V7) followed by two relatively longer waves (V7-V8-V9-V10 and V10-V1-V2-V3), to cover the three-dimensional trinuclear-cobalt-core (Fig. $3 \mathrm{~b}$ ).

The one cobalt unit in $\mathbf{C o 3}$ can be removed by the reaction with $\left[\mathrm{VO}_{3}\right]^{-}$. The reaction of $\mathbf{C o 3}$ with 5 equiv. of $\left\{\mathrm{Et}_{4} \mathrm{~N}\right\}\left[\mathrm{VO}_{3}\right]$ in acetonitrile produces $\mathbf{C o} 2$ exclusively (87\% yield based on Co3, Fig. 1a). The IR spectrum of the precipitates produced by adding ether to the above mixture solution was identical with those of Co2 (Fig. 2B), showing that Co3 is reversibly transformed into the starting Co2. The transformation reaction was expressed by eqn (2). Thus, the nucleation number control was achieved from dinuclear to trinuclear or from trinuclear to dinuclear cobalt complexes by the stoichiometric control.

$$
\begin{array}{r}
2\left\{\mathrm{Et}_{4} \mathrm{~N}\right\}_{5}\left[\mathrm{Co}_{3}\left(\mathrm{H}_{2} \mathrm{O}\right)(\mathrm{OAc}) \mathrm{V}_{10} \mathrm{O}_{30}\right]+10\left\{\mathrm{Et}_{4} \mathrm{~N}\right\}\left[\mathrm{VO}_{3}\right]+4 \mathrm{H}_{2} \mathrm{O} \rightarrow \\
3\left\{\mathrm{Et}_{4} \mathrm{~N}\right\}_{6}\left[\mathrm{Co}_{2}\left(\mathrm{H}_{2} \mathrm{O}\right)_{2} \mathrm{~V}_{10} \mathrm{O}_{30}\right]+2\left\{\mathrm{Et}_{4} \mathrm{~N}\right\} \mathrm{OAc}
\end{array}
$$

The examples of cobalt-core-containing polyoxovanadates was reported with several kinds of coordinative ligands, $[\mathrm{Co}(\mathrm{L})$ $\left.\mathrm{V}_{4} \mathrm{O}_{12}\right]^{3-}\left(\mathrm{L}=\mathrm{Cl}^{-}, \mathrm{OAc}^{-}, \mathrm{PhCOO}^{-}, \mathrm{OCN}^{-}, \mathrm{N}_{3}{ }^{-}\right) .^{40,41,64}$ It is noted that $\mathrm{Co} 2$ and $\mathrm{Co} 3$ were not obtained by the reaction of [Co(OAc) $\left.\mathrm{V}_{4} \mathrm{O}_{12}\right]^{3-}$ with $\left\{\mathrm{Et}_{4} \mathrm{~N}\right\}\left[\mathrm{VO}_{3}\right]$, and $\mathrm{Co}(\mathrm{OAc})_{2}$, respectively.

Reversible transformation between dinuclear- and trinuclearmanganese-containing decavanadates

Recently, we reported the synthesis of a trinuclear-manganesecore-containing polyoxovanadate, $\left[\mathrm{Mn}_{3}(\mathrm{OAc})\left(\mathrm{H}_{2} \mathrm{O}\right) \mathrm{V}_{10} \mathrm{O}_{30}\right]^{5-}$ (a)
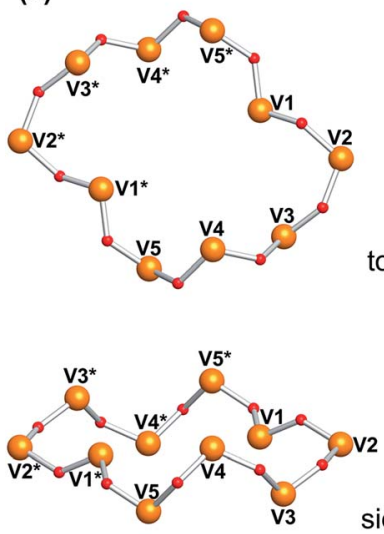

(b)

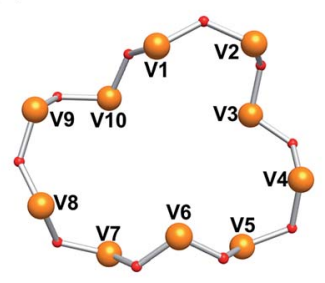

side view

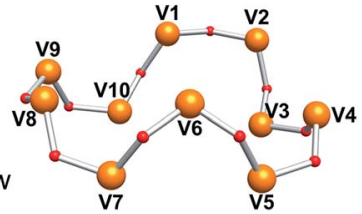

Fig. 3 Comparison of the $\mathrm{V}_{10} \mathrm{O}_{10}$ rings in (a) $\mathrm{Co} 2$ and (b) $\mathrm{Co} 3$. 
(Mn3). Compound Mn3 was isomorphous to Co3 in crystallographic data (Table $\mathrm{S} 2 \dagger) .{ }^{39}$ Because of the different ionic radii of $\mathrm{Co}^{2+}(0.745 \AA)$ and $\mathrm{Mn}^{2+}(0.830 \AA)$, the average Mn-O distances of Mn3 (2.177 $\AA$ ) were longer than the Co-O distances of $\mathrm{Co3}$ $(2.097 \AA)$. The cyclic decavanadate ligand accepted these differences by adjusting their conformation. The $\mathrm{V}-\mathrm{O}$ distances and $\mathrm{O}-\mathrm{V}-\mathrm{O}$ bond angles of Mn3 and $\mathbf{C o 3}$ were similar to each other, and each $\mathrm{V}-\mathrm{O}-\mathrm{V}$ bond angle of $\mathrm{Mn} 3$ was $2.0^{\circ}$ larger in average than that of Co3. The larger ionic radius caused the extension of the $\mathrm{V}_{10} \mathrm{O}_{10}$ ring size, for example, the distances between V2 and V8 in Mn3 and Co3 were $8.90 \AA$ and $8.75 \AA$, respectively.

Since Mn3 has the same structure of Co3, we also investigate the transformation reaction of $\mathbf{M n} 3$ to a dinuclear complex with the reaction by $\left[\mathrm{VO}_{3}\right]^{-}$ion. The IR spectrum of $\mathbf{M n} \mathbf{3}$ as a starting material was almost identical to that of Co3. By the reaction of Mn3 with 5 equiv. of $\left\{\mathrm{Et}_{4} \mathrm{~N}\right\}\left[\mathrm{VO}_{3}\right]$ with respect to $\mathrm{Mn} 3$ in acetonitrile, precipitates were obtained (yield: $88 \%$ based on Mn3, Fig. 1b). The IR spectrum of the precipitate was matched the same as that of the previously reported dinuclear-corecontaining decavanadate (Mn2) (Fig. 4B). Although the formulas of $\mathbf{M n} 2$ and $\mathbf{C o} 2$ were the same except for the presence
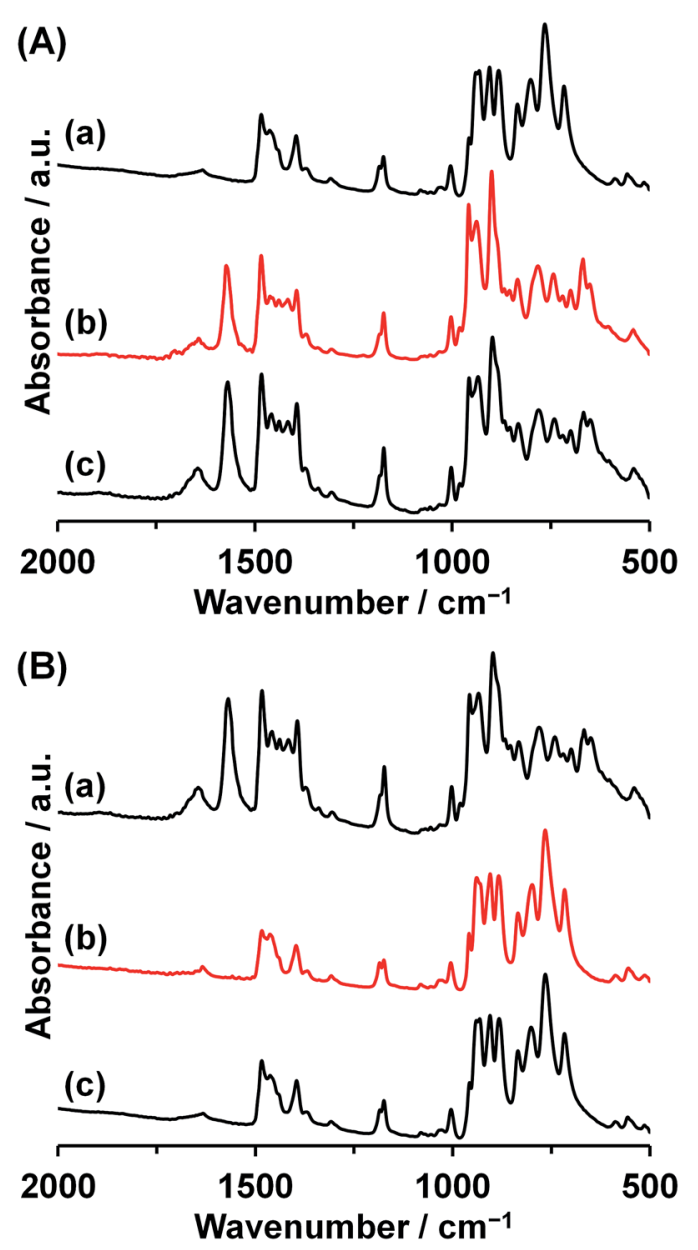

Fig. 4 (A) IR spectra of (a) Mn2, (b) Mn2 treated with 1.0 equiv. of $\mathrm{Mn}(\mathrm{OAc})_{2}$, and (c) Mn3. (B) IR spectra of (a) Mn3, (b) Mn3 treated with 5.0 equiv. of $\left\{\mathrm{Et}_{4} \mathrm{~N}\right\}\left[\mathrm{VO}_{3}\right]$, and (c) $\mathrm{Mn} 2$. of $\mathrm{H}_{2} \mathrm{O}$, the cyclic ligand configurations are totally different. While Co2 possessed a single cyclic $\mathrm{V}_{10} \mathrm{O}_{10}$ ring, Mn2 possessed two $\mathrm{V}_{5} \mathrm{O}_{5}$ rings sandwiching a dinuclear-manganese-core. The formation of Mn2 from Mn3 were expressed by eqn (3). In addition, the reverse reaction proceeded by addition of 1 equiv. of $\mathrm{Mn}(\mathrm{OAc})_{2}$ (eqn (4), Fig. 1b).

$$
\begin{gathered}
2\left\{\mathrm{Et}_{4} \mathrm{~N}\right\}_{5}\left[\mathrm{Mn}_{3}(\mathrm{OAc})\left(\mathrm{H}_{2} \mathrm{O}\right) \mathrm{V}_{10} \mathrm{O}_{30}\right]+10\left\{\mathrm{Et}_{4} \mathrm{~N}\right\}\left[\mathrm{VO}_{3}\right] \rightarrow \\
3\left\{\mathrm{Et}_{4} \mathrm{~N}\right\}_{6}\left[\mathrm{Mn}_{2}\left(\mathrm{~V}_{5} \mathrm{O}_{15}\right)_{2}\right]+2\left\{\mathrm{Et}_{4} \mathrm{~N}\right\} \mathrm{OAc} \\
\left\{\mathrm{Et}_{4} \mathrm{~N}\right\}_{6}\left[\mathrm{Mn}_{2}\left(\mathrm{~V}_{5} \mathrm{O}_{15}\right)_{2}\right]+\mathrm{Mn}(\mathrm{OAc})_{2} \rightarrow \\
\left\{\mathrm{Et}_{4} \mathrm{~N}\right\}_{5}\left[\mathrm{Mn}_{3}(\mathrm{OAc})\left(\mathrm{H}_{2} \mathrm{O}\right) \mathrm{V}_{10} \mathrm{O}_{30}\right]+\left\{\mathrm{Et}_{4} \mathrm{~N}\right\} \mathrm{OAc}
\end{gathered}
$$

We tried the synthesis of a dinuclear manganese complex with the same structure of $\mathbf{C o 2}$ by removing aquo ligands. The only difference between Mn2 and Co2 in formula is the presence or absence of aquo ligand on the dinuclear-metal-core, and the structural conversion between two types of dinuclear complexes may be possible by controlling the amount of water. By addition of water ( $\mathrm{ca} .20$ equiv. of water respect to Mn2) to the synthetic solution of $\mathbf{M n} 2$, the orange precipitates were obtained. The IR spectrum of the product was identical to that of Mn2. On the other hand, the dinuclear-cobalt complexes was not converted to a Mn2 type complex under a completely dehydrated condition.

\section{EXAFS studies}

Mn2 and Mn3 were reversibly transformed by the reaction although each compound possessed quite different anion structures. To eliminate the potential possibility that the solution state structures of Mn2 and Mn3 were different from those of the crystal structure. The EXAFS analyses were performed. The FT magnitudes of the solid and solution samples of Mn2 and Mn3 are shown in Fig. 5. The coordination number, the interatomic distance, and the Debye-Waller factor were determined by the least-squares fitting of the theoretical EXAFS function to the experimental one in $r$-space. The EXAFS parameters except for these structure parameters were estimated by using the FEFF code for the crystal structure of Mn2 and Mn3. The fitting parameters of the EXAFS results are given
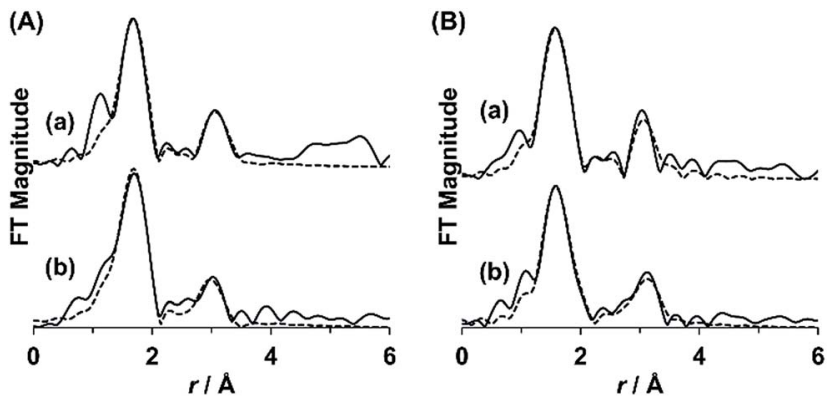

Fig. $5 \mathrm{Mn}$-K-edge Fourier transform of (A) Mn2 (a) in propylene carbonate and (b) in BN pellets and (B) Mn3 (a) in propylene carbonate and (b) in BN pellets. Experimental and simulated data are shown as solid and dotted lines, respectively. 
in Table S3. $\dagger$ The solution sample of Mn2 showed the three peaks at 2.16, 3.2, and 3.45 $\AA$ assignable to the $\mathrm{Mn}-\mathrm{O}, \mathrm{Mn} \cdots \mathrm{Mn}$, and $\mathrm{Mn} \cdots \mathrm{V}$, respectively. The peaks of the $\mathrm{Mn}-\mathrm{O}, \mathrm{Mn} \cdots \mathrm{Mn}$, and Mn $\cdots$ V were observed at 2.15, 3.20, and $3.50 \AA$, respectively, by the curve fitting of the EXAFS data for the solid sample of Mn2. The Mn-O bond lengths of Mn3 were 2.07 and 2.22 $\AA$ for the solid authentic sample, and 2.05 and $2.20 \AA$ for the solution sample. The Mn $\cdots$ Mn distances of Mn3 were 3.1 and $3.4 \AA$ for the solid sample, and 3.1 and $3.479 \AA$ for the solution sample. The Mn $\cdots$ V distances of Mn3 was $3.5 \AA$ in solution, which was slightly longer than that of solid sample. From the EXAFS analyses, the solution state structure of Mn2 and Mn3 were corresponds to the solid state structures of each compound.

\section{Magnetic studies}

The magnetic measurements of Co2, Co3, Mn2, and Mn3 were carried out using the polycrystalline sample (applied magnetic field 1000 Oe, $2-300 \mathrm{~K}$ ). The temperature dependence of $\chi_{\mathrm{M}} T$ and the field dependence of magnetization of the complexes are shown in Fig. 6a-d.

The $\chi_{\mathrm{M}} T$ value of $\mathbf{C o 2}$ at $300 \mathrm{~K}$ was $6.85 \mathrm{~cm}^{3} \mathrm{~K} \mathrm{~mol}-1$ $\left(\mu_{\text {eff }}=7.40 \mu_{\mathrm{B}}\right)$. The value indicates that the magnetic interaction is caused by the independent spin with the presence of orbital angular momenta $\left(6.75 \mathrm{~cm}^{3} \mathrm{~K} \mathrm{~mol}^{-1}, \mu=7.35 \mu_{\mathrm{B}} ; \mu=[2 \times\{L(L+1)\right.$ $\left.+4 S(S+1)\}]^{1 / 2} ; L=3, S=3 / 2\right)$, and it deviates significantly from the spin-only value $\left(3.75 \mathrm{~cm}^{3} \mathrm{~K} \mathrm{~mol}^{-1}, \mu_{\text {spin-only }}=5.48 \mu_{\mathrm{B}}\right.$; $\left.\mu_{\text {spin-only }}=[2 \times 4 S(S+1)]^{1 / 2}, S=3 / 2\right)$. When decreasing the temperature, the $\chi_{M} T$ slightly decreases to show a minimum $\left(5.70 \mathrm{~cm}^{3} \mathrm{~K} \mathrm{~mol}^{-1}\right)$ near $35 \mathrm{~K}$, but below $35 \mathrm{~K}$, the $\chi_{\mathrm{M}} T$ increases to show a maximum $\left(6.36 \mathrm{~cm}^{3} \mathrm{~K} \mathrm{~mol}^{-1}\right)$ close to $6.5 \mathrm{~K}$, and then the $\chi_{\mathrm{M}} T$ decreases to the minimum $\left(5.37 \mathrm{~cm}^{3} \mathrm{~K} \mathrm{~mol}^{-1}\right)$ at $2 \mathrm{~K}$. For the curve-fittings of the magnetic data, temperature dependent susceptibility data and field dependent magnetization data were simultaneously analyzed, considering the distortion around each cobalt(II) ion, the local spin-orbit coupling, and the exchange interaction between cobalt(II) ions. ${ }^{65-68}$ The best fitting parameters were obtained as $J=8.05 \mathrm{~cm}^{-1}, \lambda=-145 \mathrm{~cm}^{-1}$, $\kappa=0.93, \Delta=-796 \mathrm{~cm}^{-1}, \theta=-1.01 \mathrm{~cm}^{-1}$, and TIP $=997 \times 10^{-6}$ $\mathrm{cm}^{3} \mathrm{~mol}^{-1}$, where $J$ is the interaction parameter $\left(H_{\mathrm{ex}}=-J S_{1} S_{2}\right), \lambda$, $\kappa, \Delta$ are the local parameters of spin-orbit coupling, orbital reduction factor, and the axial splitting, respectively, $\theta$ is the Weiss constant, and TIP is the temperature-independent paramagnetism for each cobalt(II) ion. The definition of the local parameters is adopted from Kahn's equations. ${ }^{69}$ The obtained local parameters are within the range of typical values for octahedral high-spin cobalt(II) ions. The obtained positive $J$ value indicates the ferromagnetic interaction between cobal$\mathrm{t}(\mathrm{II})$ ions, and this is correlate well with the small Co-O-Co angle of $<93^{\circ}$. According to the obtained parameters, the slight decrease in $\chi_{\mathrm{M}} T$ from $300 \mathrm{~K}$ to $35 \mathrm{~K}$ is due to the local spin-orbit coupling, and the increase below $35 \mathrm{~K}$ is due to the ferromagnetic interaction.

The $\chi_{\mathrm{M}} T$ value of $\mathrm{Co3}$ at $300 \mathrm{~K}$ was $10.14 \mathrm{~cm}^{3} \mathrm{~K} \mathrm{~mol}^{-1}$ $\left(\mu_{\text {eff }}=9.01 \mu_{\mathrm{B}}\right)$. This value was close to the calculated value $\left(10.13 \mathrm{~cm}^{3} \mathrm{~K} \mathrm{~mol}^{-1}, \mu=9.00 \mu_{\mathrm{B}} ; L=3, S=3 / 2\right)$ estimated from the existence of the orbital and spin angular momenta
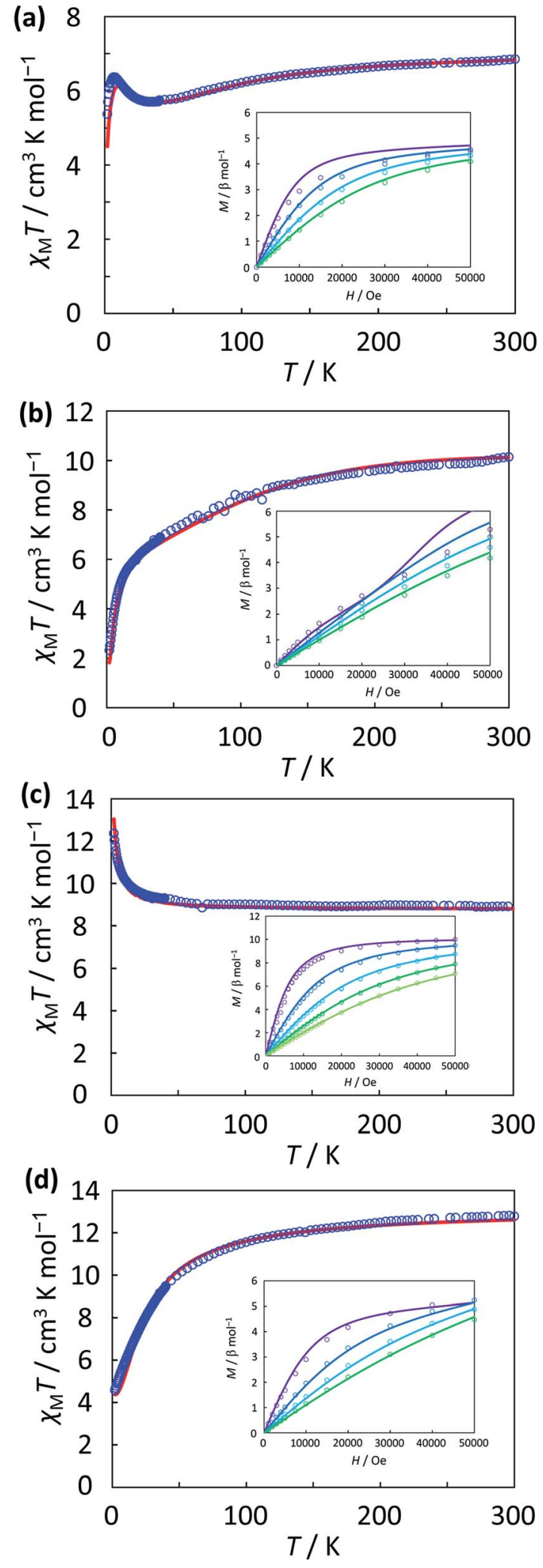

Fig. 6 Temperature dependence of $\chi_{M} T$ values of (a) Co2, (b) Co3, (c) $\mathrm{Mn2}$, and (d) Mn3 in the temperature range of 2.0-300 K under 1000 Oe field. Inset represents the field dependence of magnetization data. Solid lines represent the fitting data. 
independently. When decreasing the temperature, the $\chi_{\mathrm{M}} T$ decreases monotonously, and starting below $20 \mathrm{~K}$, the $\chi_{M} T$ drops to show a minimum $\left(2.33 \mathrm{~cm}^{3} \mathrm{~K} \mathrm{~mol}^{-1}\right)$ at $2 \mathrm{~K}$. The magnetic susceptibility data and the magnetization data were simultaneously analyzed, considering the distortion around cobalt(II) ions, the spin-orbit coupling, and the exchange interactions on the isosceles triangle model $\left(H_{\mathrm{ex}}=-J S_{\mathrm{A} 1} S_{\mathrm{A} 2}-J^{\prime}\right.$ $\left.\left[S_{\mathrm{A} 1} S_{\mathrm{B}}+S_{\mathrm{A} 2} S_{\mathrm{B}}\right]\right) .{ }^{70}$ The best fitting parameters were obtained as $J=-1.59 \mathrm{~cm}^{-1}, J^{\prime}=13.6 \mathrm{~cm}^{-1}, \lambda_{\mathrm{A}}=\lambda_{\mathrm{B}}=-159 \mathrm{~cm}^{-1}, \kappa_{\mathrm{A}}=\kappa_{\mathrm{B}}=$ $0.93, \Delta_{\mathrm{A}}=\Delta_{\mathrm{B}}=118 \mathrm{~cm}^{-1}, \theta=0.00 \mathrm{~cm}^{-1}$, and $\operatorname{TIP}_{\mathrm{A}, \mathrm{B}}=325 \times$ $10^{-6} \mathrm{~cm}^{3} \mathrm{~mol}^{-1}$. The obtained local parameters are typical values for octahedral high-spin cobalt(II) ions. The difference of the sign of the interaction in which the ferromagnetic interaction between $\operatorname{Co}(2)$ and $\operatorname{Co}(3)$ ions and the antiferromagnetic interaction between $\operatorname{Co}(1)$ and $\operatorname{Co}(2)$ ions and $\operatorname{Co}(1)$ and $\operatorname{Co}(3)$ ions reflect the difference of $\mathrm{Co}-\mathrm{O}-\mathrm{Co}$ angles: the ferromagnetic interaction was observed with the smaller angles of $\mathrm{Co}(2)-\mathrm{O}-\mathrm{Co}(3)$ in the range of $87^{\circ}$ to $93^{\circ}$, while the antiferromagnetic interaction was observed with the larger angles of Co-O-Co bridging in the range of $97^{\circ}$ to $101^{\circ} .{ }^{71-73}$

The $\chi_{\mathrm{M}} T$ value of $\mathrm{Mn} 2$ at $300 \mathrm{~K}$ was $8.88 \mathrm{~cm}^{3} \mathrm{~K} \mathrm{~mol}^{-1}$ $\left(\mu_{\text {eff }}=8.43 \mu_{\mathrm{B}}\right)$, and close to the expected value of $8.75 \mathrm{~cm}^{3} \mathrm{~K} \mathrm{~mol}^{-1}\left(\mu_{\text {spin-only }}=8.37 \mu_{\mathrm{B}}\right)$ for two noninteracting high-spin Mn(II) ions. When decreasing the temperature, the $\chi_{\mathrm{M}} T$ increases to the maximum $\left(12.35 \mathrm{~cm}^{3} \mathrm{~K} \mathrm{~mol}^{-1}, 9.94 \mu_{\mathrm{B}}\right)$ at $2 \mathrm{~K}$. The value is close to the spin-only value when two high-spin Mn(II) ions are ferromagnetically coupled $\left(15.01 \mathrm{~cm}^{3} \mathrm{~K} \mathrm{~mol}^{-1}, 10.95 \mu_{\mathrm{B}}\right)$. The data were analyzed by a conventional dinuclear model $\left(H_{\mathrm{ex}}=-J S_{1} S_{2}\right)$, and the best fitting parameters were obtained as $J=0.76 \mathrm{~cm}^{-1}, g=2.00, \theta=0.00 \mathrm{~cm}^{-1}$, and TIP $=0 \times 10^{-6} \mathrm{~cm}^{3} \mathrm{~mol}^{-1}$. Using these parameters, the magnetization data was also fitted. The week ferromagnetic interaction coincides with the small $\mathrm{Mn}-\mathrm{O}-\mathrm{Mn}$ bridging angles $\left(<97^{\circ}\right)$.

The $\chi_{\mathrm{M}} T$ value of $\mathrm{Mn} 3$ at $300 \mathrm{~K}$ was $12.78 \mathrm{~cm}^{3} \mathrm{~K} \mathrm{~mol}^{-1}$ $\left(\mu_{\text {eff }}=10.11 \mu_{\mathrm{B}}\right)$, and close to the theoretical spin-only value of $13.13 \mathrm{~cm}^{3} \mathrm{~K} \mathrm{~mol}^{-1}\left(\mu_{\text {spin-only }}=10.25 \mu_{\mathrm{B}}\right)$ for three high-spin $\mathrm{Mn}$ (II) ions. When decreasing the temperature, the $\chi_{\mathrm{M}} T$ monotonously decreases to the minimum $\left(4.58 \mathrm{~cm}^{3} \mathrm{~K} \mathrm{~mol}^{-1}\right.$, $\left.6.05 \mu_{\mathrm{B}}\right)$ at $2 \mathrm{~K}$. This value is close to the spin-only value for $S=5 / 2$ state $\left(4.38 \mathrm{~cm}^{3} \mathrm{~K} \mathrm{~mol}^{-1}, 5.92 \mu_{\mathrm{B}}\right)$. The data were analyzed by the isosceles triangle model $\left(H_{\mathrm{ex}}=-J S_{\mathrm{A} 1} S_{\mathrm{A} 2}-J^{\prime}\right.$ $\left.\left[S_{\mathrm{A} 1} S_{\mathrm{B}}+S_{\mathrm{A} 2} S_{\mathrm{B}}\right]\right)$, and the best fitting parameters were obtained as $J=-2.20 \mathrm{~cm}^{-1}, J^{\prime}=0.07 \mathrm{~cm}^{-1}, g=2.00, \theta=0.00 \mathrm{~cm}^{-1}$, and TIP $=0 \times 10^{-6} \mathrm{~cm}^{3} \mathrm{~mol}^{-1}$. Using these parameters, the magnetization data was also fitted. The obtained positive $J$ value indicates the ferromagnetic interaction between $\operatorname{Mn}(2)$ and $\mathrm{Mn}(3)$ ions, which correspond to the small $\mathrm{Mn}(2)-\mathrm{O}-$ $\mathrm{Mn}(3)$ angles $\left(88-94^{\circ}\right) .^{71,74}$ The obtained negative $J^{\prime}$ value indicates the antiferromagnetic interactions between $\operatorname{Mn}(1)$ and $\operatorname{Mn}(2)$ ions and between $\operatorname{Mn}(1)$ and $\operatorname{Mn}(3)$ ions, which correspond to the large $\mathrm{Mn}-\mathrm{O}-\mathrm{Mn}$ bridging angles $\left(99-102^{\circ}\right) .^{71,74}$ Therefore, in the ground state, $\operatorname{Mn}(2)$ and $\operatorname{Mn}(3)$ are ferromagnetically coupled and $\operatorname{Mn}(1)$ and $\operatorname{Mn}(2)$, and $\mathrm{Mn}(1)$ and $\mathrm{Mn}(3)$ are antiferromagnetically coupled, affording $S=5 / 2$ state. This is consistent with the $\chi_{M} T$ value at $2 \mathrm{~K}$.

\section{Conclusions}

The interconversion reactions between a dinuclear and a trinuclear Mn(II) or Co(II) complex are achieved by the polyoxovanadate ligand which demonstrates a versatility of the flexible inorganic ring to be able to bind each metal cores by arranging in a different conformation and a coordination mode. Each of the dinuclear complex $\left(\mathrm{Et}_{4} \mathrm{~N}\right)_{6}\left[\mathrm{M}_{2}\left(\mathrm{H}_{2} \mathrm{O}\right)_{n}\left(\mathrm{~V}_{10} \mathrm{O}_{30}\right)\right]$ ( $\mathrm{M}=\mathrm{Co}, n=2$ for $\mathbf{C o 2} ; \mathrm{M}=\mathrm{Mn}, n=0$ for $\mathrm{Mn} 2$ ) was converted to the corresponding trinuclear complex $\left(\mathrm{Et}_{4} \mathrm{~N}\right)_{5}\left[\mathrm{M}_{3}\left(\mathrm{H}_{2} \mathrm{O}\right)(\mathrm{OAc})-\right.$ $\left(\mathrm{V}_{10} \mathrm{O}_{30}\right)$ ] by adding 1 equiv. of $\mathrm{M}(\mathrm{OAc})_{2}$. The reverse reaction was also achieved by the reaction with $\left[\mathrm{VO}_{3}\right]^{-}$as a metal elimination reagent. Both of the forward and reverse reactions proceed quantitatively. In trinuclear complexes, thirteen coordination sites on the edge-shared $\mathrm{M}_{3} \mathrm{O}_{13}$ triad in $\mathbf{C o 3}$ and $\mathbf{M n} 3$ complexes are occupied from ten oxido-groups from the 10-membered vanadium ring and the rest of the three sites are coordinated by additional water and acetate ligands. The decameric ring in the transformation of cobalt complexes was maintained, while the sandwich structure by two 5-membered vanadium-rings in Mn2 has transformed to Mn3 in the same 10-membered vanadiumring of Co3. Cyclic polyoxovanadates can be regarded as flexible ligands to accept a different type of multinuclear-metalcores by rearranging and changing the conformation flexibly.

\section{Acknowledgements}

This work was supported in part by JST presto Grant Number JPMJPR16S5, Japan, JSPS KAKENHI Grant Number 15K05445, Kanazawa University SAKIGAKE Project, and Sasakawa Scientific Research Grant from the Japan Science Society. We thank Prof. N. Mizuno (the University of Tokyo) and their co-workers for their help with the magnetic measurement.

\section{Notes and references}

1 P. J. Steel, Acc. Chem. Res., 2005, 38, 243-250.

2 A. T. Wagner and P. W. Roesky, Eur. J. Inorg. Chem., 2016, 2016, 782-791.

3 M. Suga, F. Akita, K. Hirata, G. Ueno, H. Murakami, Y. Nakajima, T. Shimizu, K. Yamashita, M. Yamamoto, H. Ago and J.-R. Shen, Nature, 2015, 517, 99-103.

4 T. L. Olson, E. Espiritu, S. Edwardraja, C. R. Simmons, J. C. Williams, G. Ghirlanda and J. P. Allen, Biochim. Biophys. Acta, Bioenerg., 2016, 1857, 539-547.

5 Y. Yamada, Y. Maeda, T. Konno, K. Fujisawa and K. Okamoto, Bull. Chem. Soc. Jpn., 2000, 73, 1831-1837.

6 M.-N. Collomb Dunand-Sauthier, A. Deronzier, A. Piron, X. Pradon and S. Ménage, J. Am. Chem. Soc., 1998, 120, 5373-5380.

7 M. Lama, O. Mamula, G. S. Kottas, L. De Cola, H. StoeckliEvans and S. Shova, Inorg. Chem., 2008, 47, 8000-8015.

8 N. Yoshinari, Y. Hirai, T. Kawamoto, A. Igashira-Kamiyama, K. Tsuge and T. Konno, Chem. Lett., 2009, 38, 1056-1057.

9 W. Cullen, C. A. Hunter and M. D. Ward, Inorg. Chem., 2015, 54, 2626-2637. 
10 M. J. Burke, G. S. Nichol and P. J. Lusby, J. Am. Chem. Soc., 2016, 138, 9308-9315.

11 S. Takemoto, Y. Yamazaki, T. Yamano, D. Mashima and H. Matsuzaka, J. Am. Chem. Soc., 2012, 134, 17027-17035.

12 K. Isele, P. Franz, C. Ambrus, G. Bernardinelli, S. Decurtins and A. F. Williams, Inorg. Chem., 2005, 44, 3896-3906.

13 C. Ganesamoorthy, M. S. Balakrishna, P. P. George and J. T. Mague, Inorg. Chem., 2007, 46, 848-858.

14 M.-N. Collomb Dunand-Sauthier, A. Deronzier and A. Piron, J. Electroanal. Chem., 1999, 463, 119-122.

15 M.-N. Collomb and A. Deronzier, Eur. J. Inorg. Chem., 2009, 2025-2046.

16 G. Aromí, H. Stoeckli-Evans, S. J. Teat, J. Cano and J. Ribas, J. Mater. Chem., 2006, 16, 2635-2644.

17 C. E. Sumner, Inorg. Chem., 1988, 27, 1320-1327.

18 K. Kamata, Bull. Chem. Soc. Jpn., 2015, 88, 1017-1028.

19 M. T. Pope, Heteropoly and Isopoly Oxometalates, SpringerVerlag, New York, 1983.

20 M. Sadakane and E. Steckhan, Chem. Rev., 1998, 98, 219-238.

21 J. M. Clemente-Juan and E. Coronado, Coord. Chem. Rev., 1999, 193-195, 361-394.

22 J. M. Clemente-Juan, E. Coronado and A. Gaita-Ariño, Chem. Soc. Rev., 2012, 41, 7464-7478.

23 S.-T. Zheng and G.-Y. Yang, Chem. Soc. Rev., 2012, 41, 76237646.

24 T. Yamase, Chem. Rev., 1998, 98, 307-326.

25 C. L. Hill and C. M. Prosser-McCartha, Coord. Chem. Rev., 1995, 143, 407-455.

26 I. V. Kozhevnikov, Chem. Rev., 1998, 98, 171-198.

27 R. Neumann, in Progress in Inorganic Chemistry, John Wiley \& Sons, Inc., 1998, vol. 47, pp. 317-370.

28 U. Kortz, A. Müller, J. van Slageren, J. Schnack, N. S. Dalal and M. Dressel, Coord. Chem. Rev., 2009, 253, 2315-2327.

29 K. Suzuki, M. Shinoe and N. Mizuno, Inorg. Chem., 2012, 51, 11574-11581.

30 Y. Kikukawa, K. Suzuki, K. Yamaguchi and N. Mizuno, Inorg. Chem., 2013, 52, 8644-8652.

31 Y. Kuriyama, Y. Kikukawa, K. Suzuki, K. Yamaguchi and N. Mizuno, Chem.-Eur. J., 2016, 22, 3962-3966.

32 J. Livage, Coord. Chem. Rev., 1998, 178-180, 999-1018.

33 Y. Hayashi, Coord. Chem. Rev., 2011, 255, 2270-2280.

34 K. Y. Monakhov, W. Bensch and P. Kögerler, Chem. Soc. Rev., 2015, 44, 8443-8483.

35 T. Kurata, A. Uehara, Y. Hayashi and K. Isobe, Inorg. Chem., 2005, 44, 2524-2530.

36 S. Inami, M. Nishio, Y. Hayashi, K. Isobe, H. Kameda and T. Shimoda, Eur. J. Inorg. Chem., 2009, 5253-5258.

37 M. Nishio, S. Inami, M. Katayama, K. Ozutsumi and Y. Hayashi, Inorg. Chem., 2012, 51, 784-793.

38 M. Nishio, S. Inami and Y. Hayashi, Eur. J. Inorg. Chem., 2013, 1876-1881.

39 T. Maruyama, Y. Kikukawa, K. Kawamoto and Y. Hayashi, Eur. J. Inorg. Chem., 2017, 596-599.

40 A. Seliverstov, J. Forster, M. Heiland, J. Unfried and C. Streb, Chem. Commun., 2014, 50, 7840-7843.

41 M. Heiland, A. Seliverstov, B. Schwarz, M. H. Anjass and C. Streb, Chem.-Eur. J., 2017, 23, 2201-2205.
42 T. Kurata, Y. Hayashi and K. Isobe, Chem. Lett., 2010, 39, 708-709.

43 L. F. Chibotaru, L. Ungur, C. Aronica, H. Elmoll, G. Pilet and D. Luneau, J. Am. Chem. Soc., 2008, 130, 12445-12455.

44 Y.-Y. Zhu, C. Cui, Y.-Q. Zhang, J.-H. Jia, X. Guo, C. Gao, K. Qian, S.-D. Jiang, B.-W. Wang, Z.-M. Wang and S. Gao, Chem. Sci., 2013, 4, 1802-1806.

45 S. Ohkoshi and K. Hashimoto, J. Photochem. Photobiol., C, 2001, 2, 71-88.

46 O. Sato, Acc. Chem. Res., 2003, 36, 692-700.

47 J. B. Goodenough and K.-S. Park, J. Am. Chem. Soc., 2013, 135, 1167-1176.

48 D. J. Darensbourg, Chem. Rev., 2007, 107, 2388-2410.

49 C. Liu, B. C. Colon, M. Ziesack, P. A. Silver and D. G. Nocera, Science, 2016, 352, 1210-1213.

50 H. Sakiyama, J. Comput. Chem., Jpn., 2007, 6, 123-134.

51 H. Sakiyama, J. Comput. Chem. Jpn. Int. Ed., 2015, 1, 9-13.

52 H. Sakiyama, J. Comput. Chem. Jpn. Int. Ed., 2016, 2, 1-4.

53 H. Nakano, T. Ozeki and A. Yagasaki, Acta Crystallogr., Sect.

C: Cryst. Struct. Commun., 2002, 58, m464-m465.

54 B. Ravel and M. Newville, J. Synchrotron Radiat., 2005, 12, 537-541.

55 CrystalClear, 1.3.6, Rigaku and Rigaku/MSC, The Woodlands, Texas, USA.

56 Crystalstructure, 4.1, Rigaku and Rigaku/MSC, The Woodlands, Texas, USA.

57 C. B. Hübschle, G. M. Sheldrick and B. Dittrich, J. Appl. Crystallogr., 2011, 44, 1281-1284.

58 G. M. Sheldrick, Acta Crystallogr., Sect. A: Found. Crystallogr., 2008, 64, 112-122.

59 K. Nakamoto, Infrared and Raman Spectra of Inorganic and Coordination Compounds, Applications in Coordination, Organometallic, and Bioinorganic Chemistry, John Wiley \& Sons Ltd., 2009.

60 J. E. Tackett, Appl. Spectrosc., 1989, 43, 483-489.

61 S. G. Telfer, R. Kuroda, J. Lefebvre and D. B. Leznoff, Inorg. Chem., 2006, 45, 4592-4601.

62 R. D. Köhn, M. Haufe, G. Kociok-Köhn and A. C. Filippou, Inorg. Chem., 1997, 36, 6064-6069.

63 E. Y. Tsui, J. S. Kanady, M. W. Day and T. Agapie, Chem. Commun., 2011, 47, 4189-4191.

64 T. Kurata, Y. Hayashi and K. Isobe, Chem. Lett., 2009, 38, 218-219.

65 H. Sakiyama, R. Ito, H. Kumagai, K. Inoue, M. Sakamoto, Y. Nishida and M. Yamasaki, Eur. J. Inorg. Chem., 2001, 2027-2032.

66 H. Sakiyama, R. Ito, H. Kumagai, K. Inoue, M. Sakamoto, Y. Nishida and M. Yamasaki, Eur. J. Inorg. Chem., 2001, 2705.

67 M. J. Hossain, M. Yamasaki, M. Mikuriya, A. Kuribayashi and H. Sakiyama, Inorg. Chem., 2002, 41, 4058-4062.

68 H. Sakiyama, Inorg. Chim. Acta, 2006, 359, 2097-2100.

69 O. Kahn, Molecular magnetism, VCH, New York, 1993.

70 H. Sakiyama, H. Adams, D. E. Fenton, L. R. Cummings, P. E. McHugh and H. Okawa, Open J. Inorg. Chem., 2011, 1, 33-38.

71 Z.-Y. Du, L. Zhang, B.-Y. Wang, S. J. Liu, B. Huang, C.-M. Liu and W. X. Zhang, CrystEngComm, 2017, 19, 1052-1057. 
72 S. M. Humphrey and P. T. Wood, J. Am. Chem. Soc., 2004, 126, 13236-13237.

73 J. Luo, Y. Zhao, H. Xu, T. L. Kinnibrugh, D. Yang, 74 E. Ruiz, J. Cano, S. Slvarez and P. Alemany, J. Am. Chem. Soc., T. V. Timofeeva, L. L. Daemen, J. Zhang, W. Bao,
J. D. Thompson and R. P. Currier, Inorg. Chem., 2007, 46, 9021-9023.

1998, 120, 11122-11129. 